\section{用有色指示剂快速測定 烴族組成的色譜分析法}

快速而准确的烴族組成的分析方法是石油工業上 和石油加工研究上迫切需要解决的問題之一。最近几 年来, 利用䖝光指示剂的方法, 在文献上已有报导 [1-4]。但所用指示剂均为专利, 且使用營光指示剂的 方法需要在暗室中进行工作，这样就使这个方法不能 普掘运用。

我們根据备种化合物在硅胶上吸附的特性，闰时 利用烴类各族化合能力的差別，提出了新的用有色指 沶剂的快速烴族分析的色譜法。

对于硅胶来暿，一般烴族卤化物的吸附能力与芳 烴的吸附能力相近似，因此烴族㐫化物可以用作芳灴

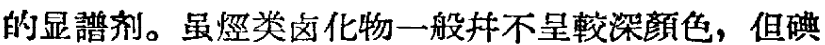
化物如三磑甲烷, 由于光綫的作用可以釋出磑元素 来，这样就可以使諠带着色; 由此三硒甲烷可以用于 烷与芳然二元系的分析, 由呈色带的长度, 可算出芳 烴在样品中的含量。我們試驗祉明，硒也可作为指示 斾, 得到同样的效果。操作是按一般的方法进行的, 显譜柱段的內徑为 $2-3$ 毫米左右，长約 1.3 米左右的 玻唡管，样品用量为 0.5 毫升左右，用酒精为脫附剂。

由于卤族与炡类化合能力不同，碘較易与䧄作 用，因此可利用这一性質来分析含有悕的样品，包括 烷一希、烯一芳二元系与烷一希一芳烴三元系的样品。对 于烷一悕二元系来說，我們可将活化的硅胶中放置少 量的碘(約 $0.05 \%$ )，使硅胶呈微紅色。将此含碘硅胶 增充在显譜杜的下段，以上全用一般活化砝胶填立。 加入烷一希二元系样品后，在烯进入含碘硅胶部分时， 即与磑化合而脫色，而烷的部分呈紅色，由烯段长度 可以楛算烯的会量。

进行烷一烯一管烴三元系的分析时, 在杪品中加入 微量三䃆甲烷, 避免与光直接接触（样品盛器可以用 棕色玻琌）。硅胶媜尤办法与烷一悕二元系分析同。当 样品全部进入显諧柱前，杜中試样用黑紙或黑布圍 繞，以避光綫与样品接触。待样品全部进入显譜杜 后，此时三元系已完全分离成三段。当光綫照在杜上 后，由于三碘甲烷的分解，芳烴部分即显示橘紅色。 悕到达显譜柱下端含碘硅胶部分时, 即使碘脫色。如 此叮看出烷段为紅色，烯段为白色，芳烴段为橘紅 色。由三段长度即可計算样品中各族的百分数。分析 悕与芳烴二元系时可不必用含碘硅胶塓充，直接由橋 江色芳㹵部分的长度算出芳烴含量。

根据多次試驗与重复，上述方法分析誤差均在 1\% 以內。一般样品的分析，連同填 充在內，在八个
小时內可完成八个分析。

\section{彭少逸 唐学溯 姜聖溜 \\ (中国科学院石油研究所) \\ 1957 年 3 月 26 日}

[1] A. L. Conrad, Anal. Chem., 20, 725(1948).

[2] D. W. Criddle, R. L. Le Tourneau, ibid, 23, 1620(1951).

[ 3 ] P. G. Harvey, R. M. Pearson, Analyst, 79, 158 (1954).

[ 4 ] H. S. Knight, S. Groenning, Anal. Chem., 28, 1949(1956).

\section{近似烟色放綫菌菌株的鍳定}

1955 年 12 月我組筸从碩和园后川柏树林地淺届 土壤中分离出两株放棧菌, 按其培养、形态及生非特 征很像烟色放菌。

合成 1 号琼脂：菌落黑褐色 $\left(n_{2}\right)$ ，后殌多次接种。 黑褐色菌落稍带紫色成分 $\left(n_{2}+M_{3}\right.$, 有时較淺), 色素 大部份透入培美基內，染为相应而較淺的顔色。气生 菌絲体烟色或深灰烟色 $\left(n_{2}+\mu_{1}, a_{2}+\mu_{1}, a_{4}+r_{1}\right)$, 有 时仅为灰色 $\left(a_{2}+a_{4}\right.$ 或 $\left.a_{4}+a_{6}\right)$ ；菌落一与生莯緤体时 常呈斑团状, 很少連为一片。狍子絲粗而不长，3-5 至 10 余，丛生。孢子柱形，相当大， $1.5-2.5 \times 1.0-$ 1.3 微米, 有时长达 3 微 米以上，显然系由横隔 分裂而成(如圖)。蒱蓗 糖天門冬素琼脂：菌落 色素不显著，呈微綠的 褐色或沙灰色 $\left(3_{6}\right)$ ，培 养基沙灰色。气生菌絲 体深灰烟色或炎色。淀 粉琼脂: 菌落䒜色或微 褐黃色; 气生菌絲体灰 色。馬鈴落塊：基質接 近菌落部分变黑, 菌落

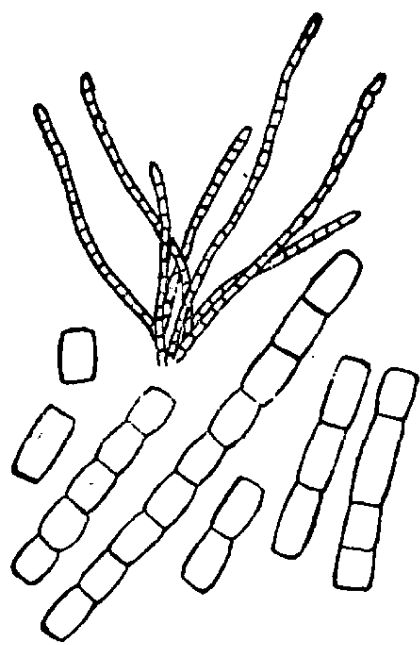
崎嶇不平，大部变黑，局部污黄。局承药落与基筫均 变为黑色或灰褐色，無气生菌絲体。

明胶液化緩慢, 液化部分变为喿色 $\left(.2_{5}\right)$ 或深褐色 $\left(\theta_{6}+n_{1}\right)$ 。牛奶腖化緩慢, 不凝固, 液体变为㬐褐色 $\left(o_{7}\right)$ ，带喑褐色 $\left(o_{7}\right)$ 或褐色 $\left(x_{7}\right)$ 环。淀粉水解力不强,

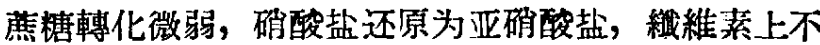
生长, 对于陽性細㮩拮抗力强。

由于菌落的黑褐色、气生菌絲的墚灰烟色、狍子 称直、抱子柱形且系由橫隔分裂形成，以及酸作用 一般微弱等特征特性，可以椇此菌就是烟色放菌 
(Actinomyces fumosus)。昷然在其色素透入培美基 內、腚粉水解力不强及有显著的拮抗作用等三点与克 垃西里尼科夫的描写不符合，但們認为也还不足以 另建新种，最多可算碳一个变种。

間逊初張国㮖 (中国科学院筆种保藏要会会) 1957 年 4 月 16 日

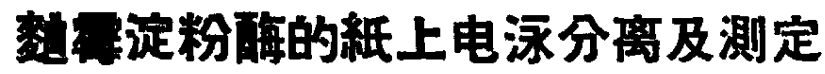

我們會比較研究了几株酒精工業上常用的姆霜淀

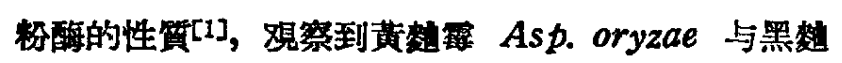

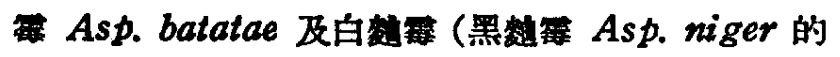

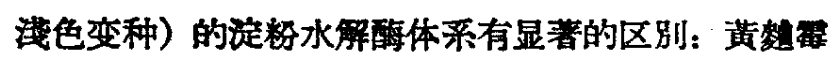

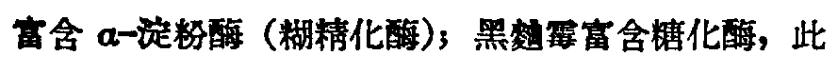

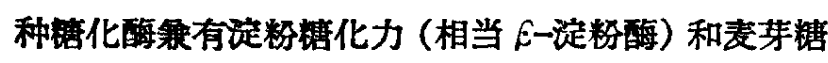
分解力(相当麦芽榶酶)。在不同的条件下处理或用硫 貶鉸分段沉拄法，都不能将这两种活性区分开来，故 进一步用林上电泳法分离抹加以测定。

所用材料为敖省水提取液, 以酒精沉淀拎冷冻干 嬠之酶制品，用时溶于水成适当之濃度。

电源为鉛登电池 $(90 \mathrm{~V})$; 滤紙为 Whatman 1

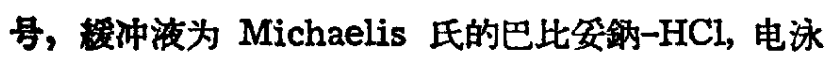

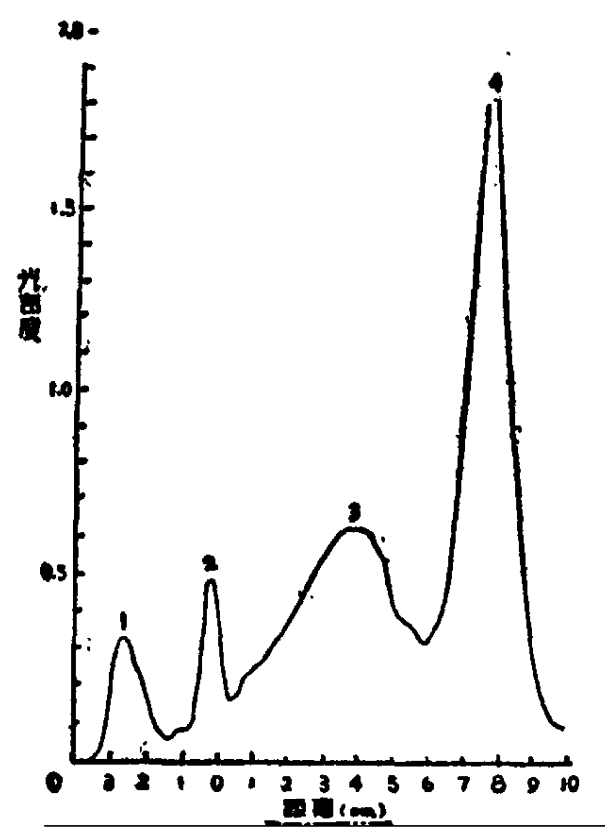

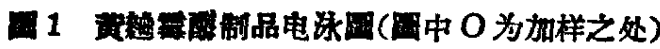
巴比安䤡 $-\mathrm{HCl}$ 冲湾 $0.1 \mathrm{M}, \mathrm{pH}=8.6$, 1.7MA/通米, $2.6 \mathrm{~V} /$ 圂米, 24 小时。

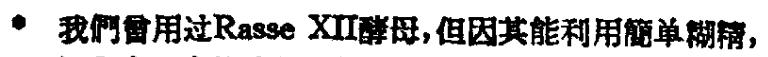

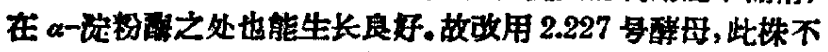

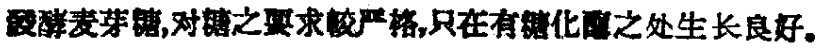

后用溴酳監染色，村用光密度計測定之。

酶活性之测定法如下: 1. 生物指示法[2,2a], 在以 腚粉为唯一碳源之琼脂培美基內接种醉母 2.227 号” 作成平板, 将电泳后之渚維条复在上面, 保温 24 小时

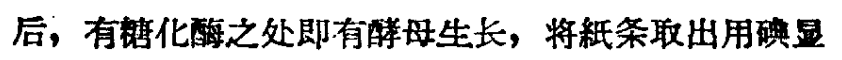
色, 無色之处即为 $\alpha$-淀粉酶之所在。2. 用化学方法 測定酶解过程之动态, 将电泳后之秖条参照染色之位 固分段竞下，放在大試管中，加 $0.2 \%$ 的腚粉或麦芽 螗 $(\mathrm{pH}=5.0)$, 于 $50^{\circ} \mathrm{C}$ 水浴中进行反应, 經过一定时 間試腚汾与碘生成之顏色，井用微量次亚碘酸盐法[3] 测定还原煻。同时用紙層离法分析水解产物作为参琞。 3, 蛋白酶之測定, 用酪素琼脂平板法, 根据透明圈制 定蛋白酶之位置。

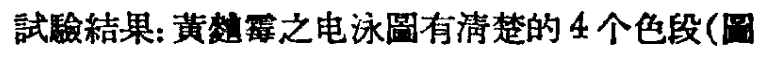
1)；黑整的区分不甚清楚，主要有两段（圖 2)。用 化学方法測定各段腚粉酶活性的結果如圖 33 麦芽㥉 酶活性之測定結果見表 1 。由此結果可以判定黄 4 (即

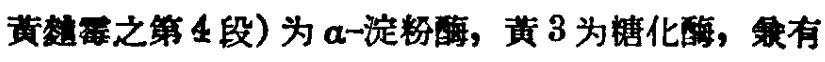
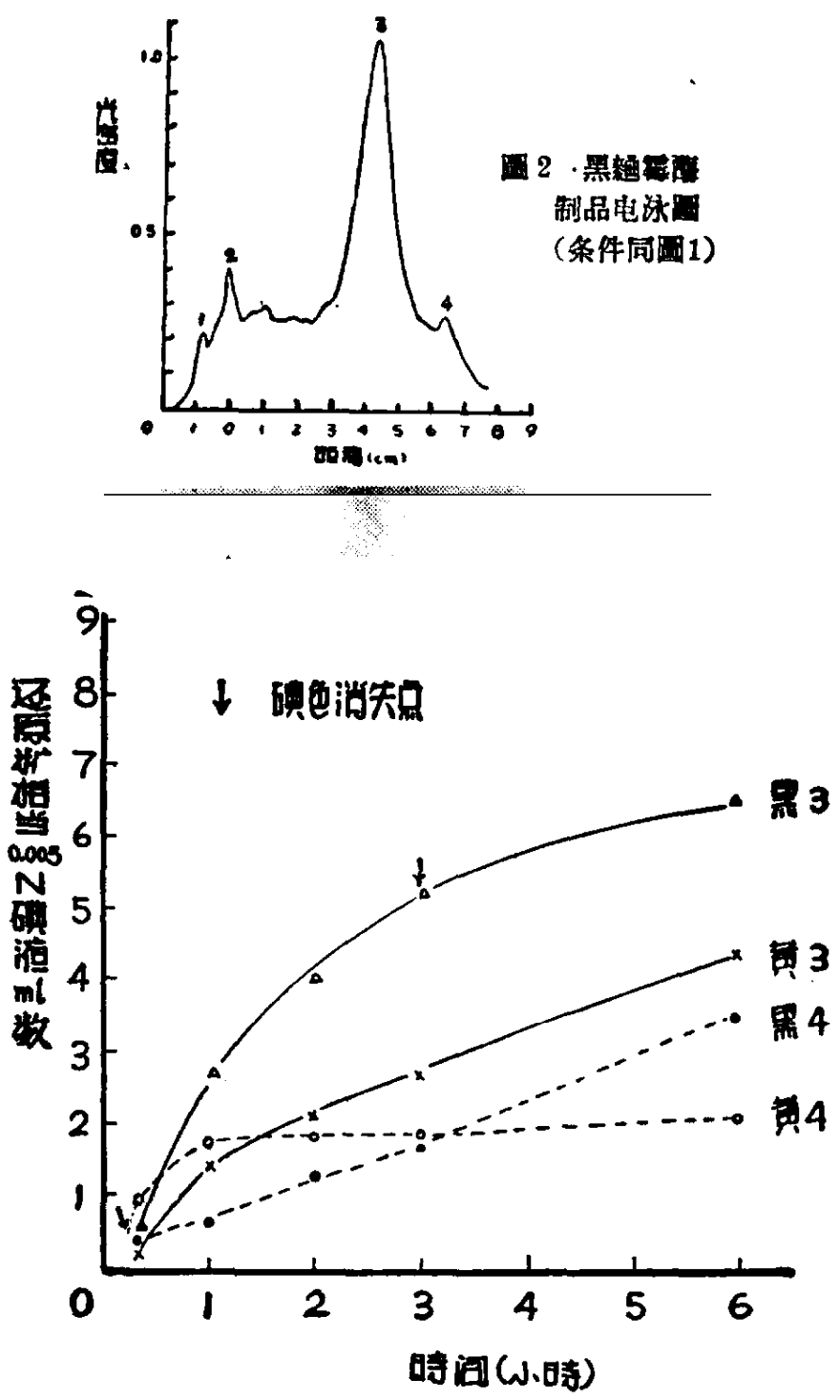

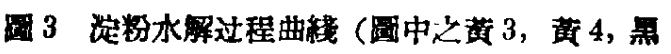
3 , 黑 4 各相当国 1 及同 2 中之 3,4 落) 